\title{
A lethal chest injury following rhinoceros attack- a case report
}

\author{
S. Shah ${ }^{1}$, N. Maharjan ${ }^{2}$, S. K. Pradhan ${ }^{2}$, P. Kafle ${ }^{2}$, D. Chapagain ${ }^{1}$, D. J. Reddy ${ }^{3}$
}

${ }^{1}$ M.Ch Resident Department of CTVS, ${ }^{2}$ Resident, Department of Surgery, ${ }^{3}$ Professor and HOD, Department of CTVS,CMS-TH Bharatpur, Nepal

\begin{abstract}
Injuries following wild animal encounters continue to be a major public health problem. Majority of such injuries are minor, however, many injuries remain undocumented. Many victim die, primarily in third-world countries, before receiving adequate medical care. Penetrating injuries to the chest following the attack by the wild animals, though rare, present a challenging problem. Though a great number of papers have been published regarding the injuries following encounter with animals, least are the lethal injuries occuring in the thoracic region and the survival out of these grave injury is very minimum. We herein present the least possible surviving case with lethal penetrating injury of the chest and left lung following the goring by the rhinoceros.
\end{abstract}

Key words: Animal attack, rhinoceros, open thoraco-pleural injury.

\section{Introduction}

Injuries from animal attack continue to be a major public health problem. Animals can cause injuries by various mechanisms that include bite, sting, crush, gore, stomp, buck off, fall on, peck, or scratch. Millions of injuries, hundreds of thousands of emergency department visits, and thousands of hospitalizations, at a cost of hundreds of millions of dollars, occur yearly because of animal encounters. Fortunately, the majority of such injuries are minor. However, many injuries remain undocumented and many people die, primarily in third-world countries, before receiving adequate medical care. We report a rare case of lethal penetrating chest injury with open thoraco-plueral air sucking injury and lung contusion following attack of a wild rhinoceros. Patient survived because of prompt intervention and management.

Correspondence: S. Shah

E-mail: santshah@hotmail.com

\section{Case details}

A 45 years old farmer from Dumkibas-7, Nawalparasi presented to the casualty department of CMSTH, Bharatpur at of 20/11/2011 with the alleged history of attack by the Rhinoceros at around 11:00 am of the same day. The rhinoceros had lifted and thrown him $10 \mathrm{ft}$ away with the horn penetrating his chest wall on left side. On presentation he had 14/15 GCS with history of loss of consciousness for uncertain period and no other signs of head injury elicited. A positive history of approximately 2 liters of blood loss was present. On primary survey his blood pressure was $80 / 60 \mathrm{mmHg}$ so active fluid resuscitaion was started, his airway was intact but had labourous breathing with fluctuating saturation. Thus after full counselling and consent, he was intubated and supported with bain circuit. On secondary survey his GCS was 14/15 on presentation and changed to $7 \mathrm{ET} / 15$ after intubation. 
His pupils were bilaterally $4 \mathrm{~mm}$ and equally reactive to light. His other vital parameters were within normal limit. On auscultation of chest, decreased air entry was noted in the left side with normal cardiovascular status and abdominal examination revealed of soft, non-tender abdomen with mild distension with normal bowel sound.

On local examination, lacerated wound of $7 \mathrm{~cm}$ long over the frontal region, $6 \times 2 \mathrm{~cm}$ over the anterior aspect of left axillary region, $12 \times 5 \mathrm{~cm}$ deep laceration over the lateral aspect of left chest wall with multiple ribs fracture with exposure of traumatic lung and diaphragm along with pulsatile movement of the heart was noted (fig. 1). There was also deep laceration over the posterior aspect of left lumbar area and superficial cut injury over the right elbow and medial aspect of the right thigh.

Fig. 1: Wound on chest wall.

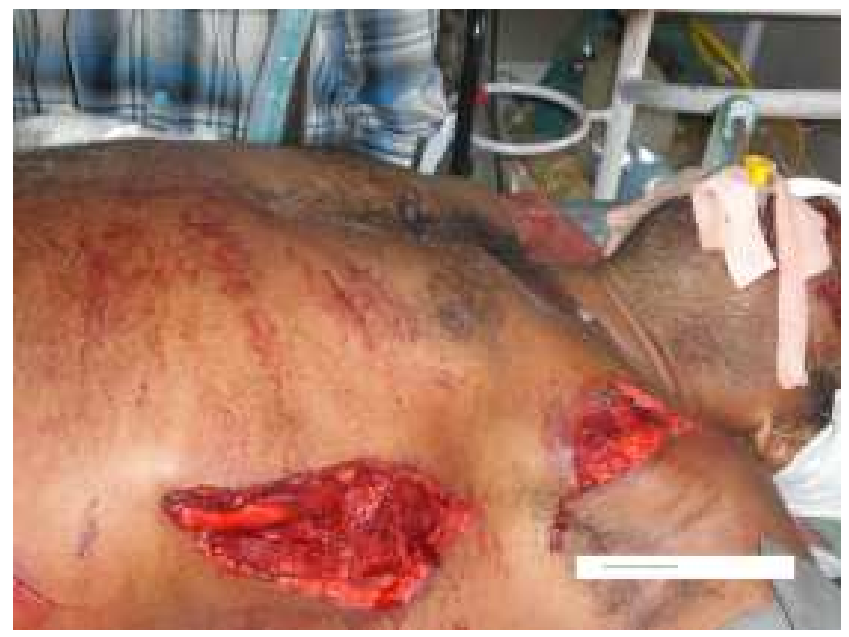

Blood investigations were sent. Under intra-venous and local anesthesia, the examination revealed of deep laceration with open chest injury with minor leak and minimal bleeding from both lobes of the left lung and the intact diaphragm was seen. The pulsatile movement of the heart was also noticed. (Fig. 2)
Fig. 2: Examination under sedation

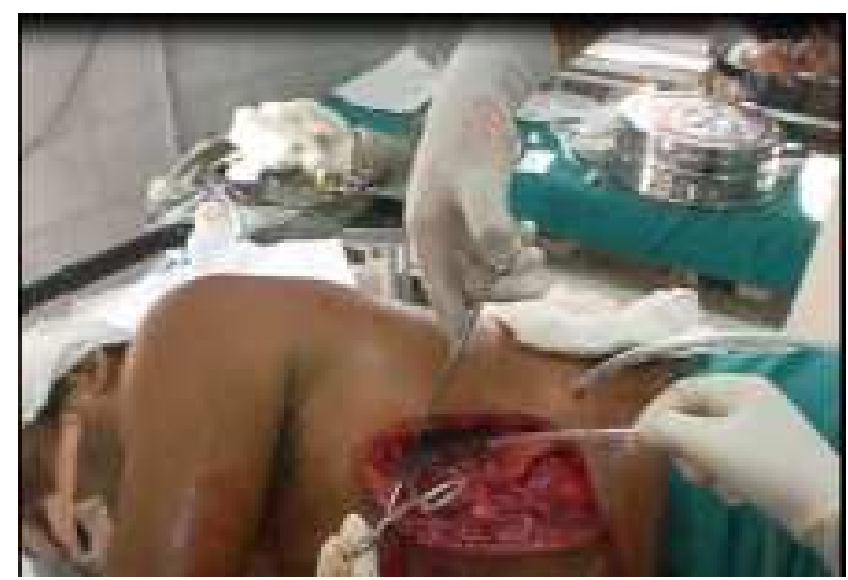

Wound debridement was done and after proper hemostasis, thoracostomy tube was inserted and the chest wall was closed in layers with Vicryl 3-0. Skin was closed with prolene 2-0. Other injuries were managed simultaneously and then was shifted to ICU under IPPV mode ventillator after doing CT scan head and chest $\mathrm{x}$-ray. Three pint of whole blood was transfused. Post operatively he recovered gradually and was finally extubated on his 3rd post operative day (Fig. 3). With further close observation and conservative management, he regained his health to optimum level and was discharged on 15th post operative day. On successive follow up, he remained asymptomatic.

Fig. 3: Patient during recovery phase.

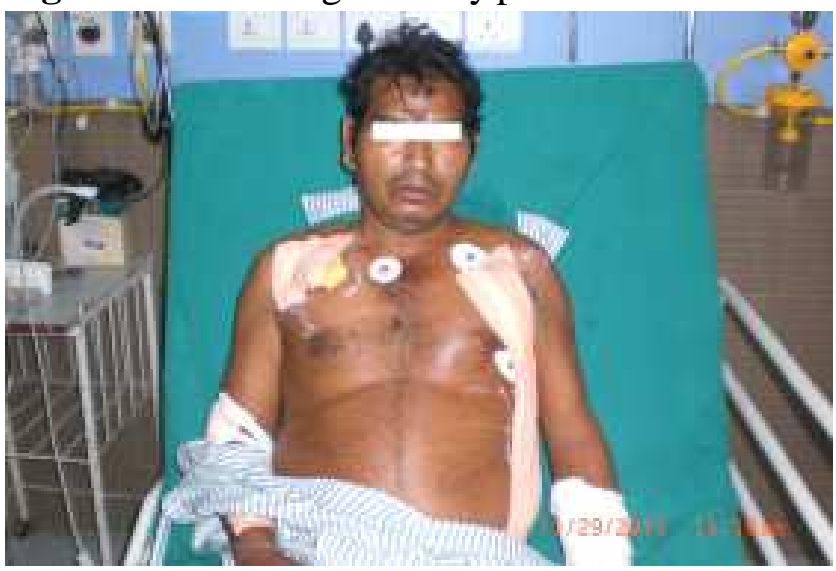


Details of one horn rhinoceros

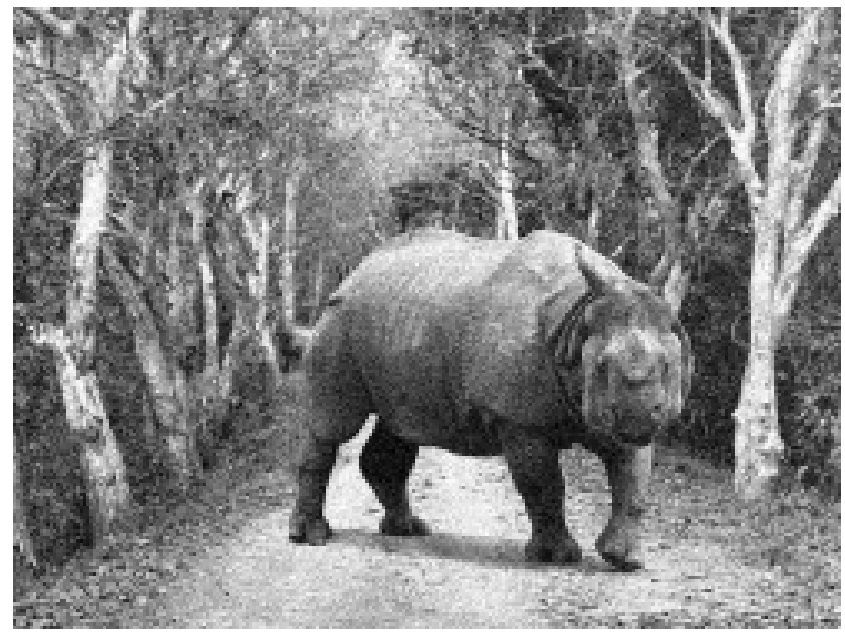

The Indian Rhinoceros or the Greater One-horned Rhinoceros (Rhinoceros unicornis) is now found almost exclusively in Nepal and North-Eastern India. It is confined to the tall grasslands and forests in the foothills of the Himalayas.

The Indian Rhinoceros has thick, silver-brown skin which creates huge folds all over its body. Its upper legs and shoulders are covered in wart-like bumps, and it has very little body hair. Fully grown males are larger than females in the wild, weighing from 2,500$3,200 \mathrm{~kg}(5,500-7,100 \mathrm{lb})$. The Indian rhinoceros stands at 1.75-2.0 metres (5.75-6.5 ft). Female Indian rhinoceros weigh about $1,900 \mathrm{~kg}$ and are 3-4 metres long. The record-sized specimen of this rhinoceros was approximately $3,800 \mathrm{~kg}$. The Indian rhinoceros has a single horn that reaches a length of between 20 and $100 \mathrm{~cm}$. Its size is comparable to that of the white rhinoceros in Africa.

\section{Discussion}

Population explosion and advancing civilization rapidly increases the demand for more and more land for agriculture and industry. Fast receding trees, shrinking and fragmenting wild animal habitat are forcing the wild animals close to the human population thus increasing the incidences of human and wild animal conflict. ${ }^{1}$ Interaction with animals of all kinds may result in human fatalities from a wide variety of causes ranging from blunt force trauma to envenomation. ${ }^{2}$ Though the management of injuries resulting from dog bites, zoo animal attacks, and trampling or kicking by large mammals such as cows, moose, or deer, is facilitated by well-developed emergency response systems in the western world, more unusual wild animal attacks and the complex injuries that result may pose a challenge to surgeons practicing in resource-limited settings. ${ }^{3}$ There is significant risk of sustaining injury, often severe, from rearing of domestic animals like cows, bulls and buffaloes. A combination of education and proper human handling of these domestic animals may decrease the incidence of this injuries. ${ }^{4}$

Animal related injuries defined as bite or claw wound from a pet or wild animal are most common causes of morbidity and mortality particularly in the rural tropics and discussed as neglected public health problems throughout the world. Animal-related injury is known to be common in rural regions however; studies in urban centres are only related with equestrian trauma due to its frequency and association with serious injuries. Every type of injury may lead to characteristic consequences and causes specific problems for the treatment. $^{5}$

Mammal bite injuries include puncture wounds, lacerations, and avulsions and crush injuries may result in infection, transmission disease, disfigurement, serious injury or death. Effective management requires rapid medical evaluation and may necessitate surgical intervention and prophylactic antibiotic therapy. As bite 
S. Shah, A lethal chest injury following rhinoceros attack- a case report

wounds are microbiologically diverse and most often polymicrobial in nature, selection of an appropriate antibiotic regimen requires knowledge of common pathogens. Close clinical follow-up is recommended to minimize the risk of late complications. A patient's tetanus status and risk of rabies must also be identified and appropriate immunoprophylaxis should be administered. Injuries caused by large animals, such as horses or cows, are treated as high-energy injuries. this is confirmed by a statistically significant higher percentage of hospitalizations, compared with the consequences of other animal attacks. 5,6

Injuries caused by ocean-dwelling creatures are usually considered to be rare and exotic. Such injuries, however, are an acknowledged occupational hazard for many people who catch fish from tropical seas. ${ }^{7}$ As in our case where open thoraco-pleural injury was present, there are cases reported of such injury by catfish stings and swordfish attack in the fishermen. ${ }^{8,9}$ Attacks on humans by sharks are rare events, with only 50 to 100 events recorded worldwide per year, many of which involve only minor injury. ${ }^{10}$

\section{Conclusion}

A wide variety of injury can be seen following the encounter with the wild or domesticate animals ranging from minor abrasion to loss of human life. Public awareness regarding these kinds of injuries should be carried out with high alert and despite of the avoidance, if the accident happens then the best way of saving the life is immediate and prompt management at the site of injury or if possible at the nearby hospital. As in our case where there is lethal injury, the simple but prompt management could save a life.

\section{References}

1. S.K. Das, S. Chattopadhyay. Human fatalities from wild elephant attacks - a study of fourteen cases. $J$. Forensic Leg. Med. 2011;18;154-7.

2. D. Bury, N. Langlois, R.W. Byard. Animal related fatalities - part 1: characteristic autopsy findings and variable causes of death associated with blunt and sharp trauma. J. Forensic Sci. 2011; doi: 10.1111/j.15564029.2011.01921.x

3. K.B. Mitchell, V.R. Kotecha, A. Chandika. Bush animal attacks: management of complex injuries in a resourcelimited setteing. World J. Emer. Surg. 2011;6:43.

4. S.M. Bakkannavar, F.N.P. Monteiro, P. Bhagavath et al. Death by attack from a domestic buffalo. J. Forensic Leg. Med 2010;17;102-4.

5. M. Moini, A. A. Peyvandi, M. R. Rasouli et al. Pattern of animal related injuries in Iran. Acta Medica Iranica. 2011;49:163-8.

6. R. L. Langley. Attacks on humans in the United States. Wilderness Environ. Med. 2008;16:119-24.

7. P. G. Barss. Injuries caused by garfish in Papua New guinea. Br. Med. J. 1982;284:77-9.

8. V. Haddad, R. Alves de souza, P. S. Auerbach. Marine catfish sting causing fatal heart perforation in a fisherman. Wilderness Environ. Med. 2008;19:114-8.

9. J. M. G. Caravajal, J. J. M. Madueno, B. B. Gomez et al. Swordfish attack: an unusual cause of penetrating thoracic wound. Eur. J. Cardio-thoracic Surg. 2002;21:926.

10. R. W. Byard, R. A. James, K. J. Heath. Recovery of human remains after shark attack. Am. J. Forensic Med. Pathol. 2006;27:256-9. 